\title{
Lycium barbarum polysaccharides attenuates the apoptosis of hippocampal neurons induced by sevoflurane
}

\author{
YUHAI XIE and XUEJUN WANG
}

Department of Anesthesiology, Qinghai Red Cross Hospital, Xining, Qinghai 810000, P.R. China

Received October 24, 2017; Accepted March 21, 2018

DOI: $10.3892 /$ etm.2018.6426

\begin{abstract}
Following the application of inhalational anesthetics, including sevoflurane, patients may suffer from neural injury. The present study was conducted to explore the mechanism involved in Lycium barbarum polysaccharides (LBP) treatment of sevoflurane injured hippocampal neurons. Primary hippocampal neurons were isolated from Sprague Dawley embryonic rats. Thle Cell Counting Kit-8 (CCK-8) assay was used to detect cell viability. Furthermore, flow cytometry (FCM) was used to determine cell proliferation and apoptosis rates. Reverse transcription-quantitative polymerase chain reaction (RT-qPCR) and western blot analysis were applied to detect the expression levels of apoptosis-related factors, including activated-Caspase-3, B-cell lymphoma/leukemia-2 (Bcl-2) and Bcl-2 associated X (Bax), phosphorylated extracellular signal-regulated kinase $1 / 2$ (p-ERK1/2) and total ERK1/2. The results showed that LBP promoted cell viability and cell proliferation but inhibited cell apoptosis in neurons injured with $3 \%$ sevoflurane, in dose-dependent manners $(100,200$ and $400 \mu \mathrm{g} / \mathrm{ml})$. LBP increased the expression levels of Bcl-2 and p-ERK1/2, and decreased levels of activated-Caspase-3 and Bax in a dose-dependent manner in hippocampal neurons that were injured with sevoflurane. In addition, ERK1/2 inhibitor reversed the above phenomenon in $400 \mu \mathrm{g} / \mathrm{ml} \mathrm{LBP}$ and $3 \%$ sevoflurane-treated hippocampal neurons. Therefore, the present study indicated that LBP protected hippocampal neurons from sevoflurane injury, including aberrant cell apoptosis, via the ERK1/2 pathway.
\end{abstract}

\section{Introduction}

Sevoflurane is one of the most prominent inhalational anesthetics used in cesarean delivery and pediatric clinical application, for its rapid induction and recovery properties. The critical vulnerable period of anesthetic neurotoxicity

Correspondence to: Dr Xuejun Wang, Department of Anesthesiology, Qinghai Red Cross Hospital, 55 South Avenue, Xining, Qinghai 810000, P.R. China

E-mail: xuejunwang25@163.com

Key words: Lycium barbarum polysaccharides hippocampus neuron, sevoflurane, apoptosis, extracellular signal-regulated kinase depends on rapid synaptogenesis, and lasts from mid-gestation to several years after birth $(1,2)$. Recent retrospective cohort studies demonstrated that anesthesia application in young children younger than 3 years old could lead to behavioral and developmental cognitive disorders (3-5). Sevoflurane neurotoxicity in immature brain is associated with alterations in behavior, spatial learning, memory and reading, writing, math learning disabilities, even effects later in adulthood (6-10). More evidence suggested that sevoflurane could induce neuronal apoptosis of developing brain $(11,12)$. For the frequent application of sevoflurane in anesthetics exposure for childbirth and surgeries to prevent pain, it is urgent to find effective remedy to prevent anesthetic neurotoxicity.

Lycium barbarum, fruit of wolfberry, is commonly applied as food addictive and traditional medicinal herb in many countries, especially China and other Asian countries (13). Lycium barbarum polysaccharides (LBPs), the main effective component of Lycium barbarum, possess a variety of beneficial effects in anti-aging, anti-cancer, immune modulation and neuroprotection (14-17). LBP is found to decrease oxidative stress in hippocampus, promote cell proliferation and neurons differentiation $(18,19)$. It is also reported to enhance neurogenesis in hippocampus and subventricular zone, to improve cognition via apoptosis regulation in hippocampal neurons under stress, and to prevent cognitive and memory deficits in scopolamin-treated rats (20-24). However, whether and how LBP protects neurons from injury of sevoflurane is still unclear.

Apoptosis, also called programmed cell death, eliminates dysfunctional or superfluous cells to maintain normal tissue functions. However, abnormal apoptosis could induce cell injury or death. Sevoflurane has been reported to promote the activation of cysteine aspartate-specific protease (Caspase) and apoptosis pathway (11,25). Extracellular signal-regulated kinase 1/2 (ERK1/2), a critical member of mitogen-activated protein kinase (MAPK) cascades, plays a prominent role in cell survival and death. Recent researches have demonstrated that ERK1/2 plays positive roles in neuroprotective processes. Sevoflurane neurotoxicity in immature brain is related to ERK1/2 signaling pathway and apoptosis related factors such as Caspase-3, B-cell lymphoma/leukemia-2 (Bcl-2) and Bcl-2 associated X (Bax) (6-8). It would be interesting to know whether LBP effects on sevoflurane-injured neurons through ERK1/2 pathway.

In conclusion, we constructed sevoflurane-injured rat hippocampal neuron model to validate possible function of LBP on cell apoptosis induced by sevoflurane. Furthermore, we 
also measured the role of ERK1/2 MAPK signaling pathway on it. It may provide novel light for clinical application of LBP as remedy for anesthetic neurotoxicity.

\section{Materials and methods}

Primary nerve cells cultures. Adult female Sprague-Dawley (SD) rats, weighing 200-300 g, were purchased from Beijing Vital River Company (Beijing, China) and raised for 14 days under normal environment $\left(22-24^{\circ} \mathrm{C}, 55-65 \%\right.$ humidity, $12-\mathrm{h}$ light/dark cycle) after mating between female and male rats. Then the embryos were isolated for following experiments. The present study was approved by Institutional Animal Care and Use Committee of Qinghai Red Cross Hospital (Xining, China). After being sacrificed by cervical dislocation, the rats were immersed and disinfected in alcohol. The pregnant uterus were exposed and cut off under aseptic conditions, the fetus was removed, and the hippocampus tissues were isolated and digested by $0.125 \%$ trypsin for $30 \mathrm{~min}$, and nerve cells were collected and cultured in Neuralbasal media (MTI-GlobalStem, Gaithersburg, MD, USA) supplemented with $2 \%$ B27, $10 \mathrm{mmol} / 1 \mathrm{HEPES}$, and $0.5 \mathrm{mmol} / \mathrm{l} \mathrm{L}$-glutamine, in $5 \% \mathrm{CO}_{2}$-containg incubator at $37^{\circ} \mathrm{C}$. Cell culture media was changed every 3 days. Cell morphology was observed by DMi8 optical microscope (Leica Microsystems GmbH, Wetzlar, Germany) after being cultured for 3 and 7 days, respectively.

Primary hippocampal neurons cultured for 7 days were pre-treated with LBPs with different concentrations (100, 200, 400 and $600 \mu \mathrm{g} / \mathrm{ml}$ ) for $6 \mathrm{~h}$, and injured by $3 \%$ sevoflurane [Baxter Healthcare (Shanghai) Co., Ltd., Shanghai, China] gas mixture of $95 \% \mathrm{O}_{2}$ and $5 \% \mathrm{CO}_{2}$ subsequently, the flow rate of which was delivered at $21 / \mathrm{min} .3 \%$ seveflurane was used to construct the injury model, the concentration of which was just higher than that commonly used in clinical application and was commonly used in researches too $(6,26)$, The groups were named LBP100+SEV, LBP200+SEV, LBP400+SEV, LBP600+SEV groups, respectively, Cells treated with $3 \%$ sevoflurane gas alone were named SEV group, Cells treated with $400 \mu \mathrm{g} / \mathrm{ml}$ LBPs were named LBP400 group, and cells without any treatment were considered as Control group.

In addition, for the best repairing effect, LBP400+SEV cells were chosen to be treated with $5 \mu \mathrm{mol} / 1 \mathrm{ERK} 1 / 2$ inhibitor PD98059 (Merck, Germany) $1 \mathrm{~h}$ before $400 \mu \mathrm{g} / \mathrm{ml}$ LBP treatment (ERK1/2 inhibitor+LBP400+SEV group). The changes were compared to that in Control, SEV, LBP400+SEV groups.

Cell Counting Kit-8 (CCK-8) assay. Cell viabilities of primary hippocampal neurons in different groups (Control, SEV, LBP100+SEV, LBP200+SEV, LBP400+SEV, LBP600+SEV groups) were determined by CCK- 8 assay (Beyotime Institute of Biotechnology, Haimen, China) in dedicated times (2, 4 and $6 \mathrm{~h}$ ), according to the manufacturer's protocols. Briefly speaking, following the determined treatment, cells were seeded in 96-well plates and reacted with $20 \mu \mathrm{l} \mathrm{CCK}-8$ reagent for $1 \mathrm{~h}$ in $5 \% \mathrm{CO}_{2}$-containing incubator at $37^{\circ} \mathrm{C}$. CCK-8 is a yellow-colored dye, which can be reduced by succinate dehydrogenase in mitochondria of living cells. forming soluble blue-purple formazan and depositing in cells, whereas dead cells do not have this function. The optical density (OD) values were measured by a microplate reader (Omega Bio-Tek, Inc., Norcross, GA, USA) at $450 \mathrm{~nm}$.

Carboxyfluorescein diacetate succinimidyl ester (CFSE) assay. Mature neurons are terminal differentiation cells. However, the embryo hippocampus neurons have the ability of proliferation and differentiation (25,27-29). CFSE cell proliferation kit (Invitrogen, USA) was used to analyze cell proliferation abilities of different groups (Control, SEV, LBP100+SEV, LBP200+SEV, LBP400+SEV groups), which detected both living and dead cells, according to the manufacturer's protocols. Cells were resuspended to $1 \times 10^{6} / \mathrm{ml}$ in $1 \mathrm{ml}$ preheated phosphate buffer solution (PBS) in sterile centrifuge tubes. $2 \mu \mathrm{l}$ CFSE (5 mmol/l) stocking reagent was added into cell suspension to the final concentration of $10 \mu \mathrm{mol} / 1$, then cells were incubated at $37^{\circ} \mathrm{C}$ for $10 \mathrm{~min}$ and then in $10 \mathrm{ml}$ icy culture media for $5 \mathrm{~min}$ in dark. Finally, cells were inoculated in 24-well plates $\left(1 \times 10^{5} /\right.$ well $)$ and incubated with $5 \% \mathrm{CO}_{2}$ at $37^{\circ} \mathrm{C}$, then cells were digested, collected and detected by FACS Calibur flow cytometer (BD Biosciences, Franklin Lakes, NJ, USA), with the whole process avoiding light.

Apoptosis detection. The apoptosis rates of hippocampal neurons in different groups (Control, SEV, LBP100+SEV, LBP200+SEV, LBP400+SEV groups) were determined by Annexin V/PI (propidine iodide) double-stain assay, according to the manufacturer's instructions (BioVision, Inc., Milpitas, CA, USA). Phosphatidylserine exposed to the outside of cell membrane in early stage of apoptosis could be detected by Annexin V/FITC (fluorescein isothiocyanate), and DNA within membrane-injured cells could be detected by PI in the late-stage of apoptosis. The combination of them could effectively detect apoptotic cells. In the experiment, cells were resuspended by $100 \mu \mathrm{l}$ binding buffer to the final concentration of $1 \times 10^{6}$ cells $/ \mathrm{ml}$. Then $5 \mu \mathrm{l}$ Annexin V/FITC and $10 \mu \mathrm{l}$ PI $(20 \mu \mathrm{g} / \mathrm{ml})$ were added in. After the incubation for $15 \mathrm{~min}$ away from light at room temperature, cells were analyzed by a flow cytometer (BD Biosciences), with $488 \mathrm{~nm}$ as exciting light wavelength, and $515 \mathrm{~nm}$ (FITC), $560 \mathrm{~nm}$ (PI) as detecting light wavelengths.

Reverse transcription-quantitative polymerase chain reaction $(R T-q P C R)$. RT-qPCR was performed to analyze the mRNA expression levels of apoptosis-related factors such as Caspase-3, Bax, Bcl-2 in different groups, including Control, SEV, LBP100+SEV, LBP200+SEV, LBP400+SEV and ERK1/2 inhibitor+LBP400+SEV groups. GAPDH was considered as internal reference. Firstly, total RNA was extracted by TRIzol (Invitrogen; Thermo Fisher Scientific, Inc., Waltham, MA, USA) and reversely transcribed to cDNA with a first strand cDNA kit (Takara Bio, Inc., Otsu, Japan), according to the protocols provided by manufacturer. PCR amplification was conducted using the SYBR Premix Ex Taq kit (Takara Bio, Inc.). Briefly, after pre-denaturation at $95^{\circ} \mathrm{C}$ for $30 \mathrm{sec}$, amplification of 40 cycles were conducted: denaturation at $95^{\circ} \mathrm{C}$ for $5 \mathrm{sec}$, annealing/extension at $60^{\circ} \mathrm{C}$ for $30 \mathrm{sec}$, which was performed in ABI 7300 Thermocycler (Applied Biosystems; Thermo Fisher Scientific, Inc.) The primer sequences were as follows: Caspase-3 (sense: 5'TGG AATGTCAGCTCGCAATG3' and antisense: 5'CAGGTC CGTTCGTTCCAAAA3'); Bax, sense: 5'AGATCATGAAGA 


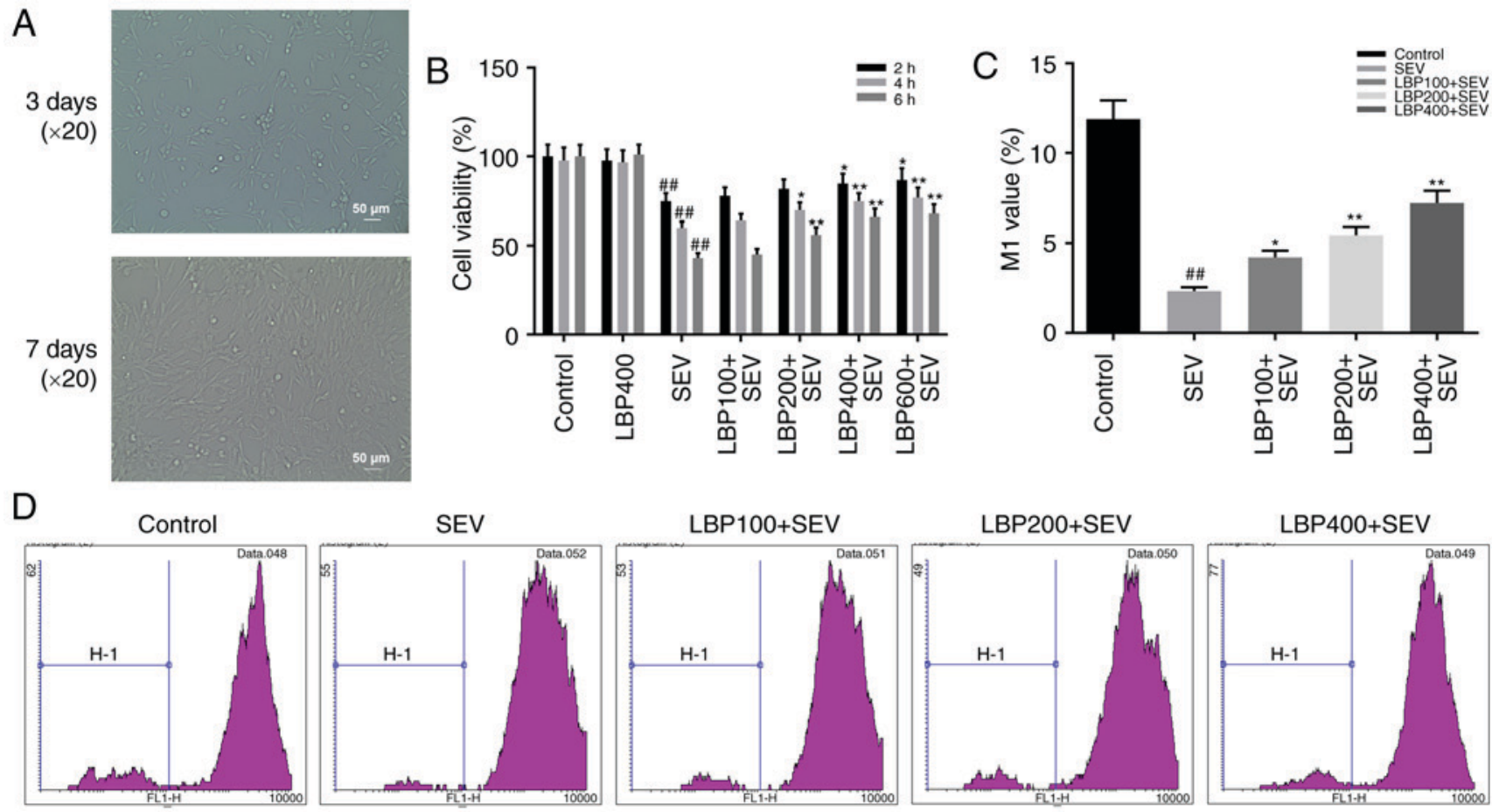

Figure 1. LBP promoted cell viability of hippocampal neurons injured by sevoflurane. (A) Cell morphology of hippocampus primary neurons separated from SD embryonic rats was observed under light microscopy, after 3 and 7 days culture. (B) CCK-8 assay was used to detect function of LBP with different concentrations $(100,200,400$ and $600 \mu \mathrm{g} / \mathrm{ml})$ on cell viability of $3 \%$ sevoflurane treated neurons in different groups (Control, LBP400, SEV, LBP100+SEV LBP200+SEV, LBP400+SEV, LBP600+SEV), at different times (2, 4 and 6 h). (C and D) CFSE assay was conducted to verify the promotion function of LBP on cell differentiation of neurons, after $6 \mathrm{~h}$ treatment of sevoflurane. ${ }^{\# \#} \mathrm{P}<0.01$ vs. Control group, ${ }^{~} \mathrm{P}<0.05,{ }^{* *} \mathrm{P}<0.01$ vs. SEV group. LBP, Lycium barbarum polysaccharides; SD, Sprague-Dawley; CCK-8, Cell Counting Kit-8; CFSE, carboxyfluorescein diacetate succinimidyl ester.

CAGGGGCC3' and antisense: 5'ATCCTCTGCAGCTCC ATGTT3'; Bcl-2, sense: 5'AACTCTTCAGGGATGGGG TG3' and antisense: 5'GCTGGGGCCATATAGTTCCA3'; GAPDH, sense: 5'AGTCTACTGGCGTCTTCACC3' and antisense: 5'CCACGATGCCAAAGTTGTCA3').

Western blot analysis. Western blotting was conducted to measure protein levels, including apoptosis related factors (active-Caspase-3, Bax, Bcl-2) and p-ERK1/2 (phosphorylated ERK1/2), t-ERK1/2 (total-ERK1/2), in different groups including Control, SEV, LBP100+SEV, LBP200+SEV, LBP400+SEV and RK1/2 inhibitor+LBP400+SEV groups. Briefly speaking, proteins were firstly extracted and the quantities were determined by BCA assay (Beyotime Institute of Biotechnology,). Then they were concentrated and separated by sodium dodecyl sulfate-polyacrylamide gel electrophoresis (SDS-PAGE), and electrotransfered onto a polyvinylidene fluoride (PVDF) membrane (EMD Millipore, Billerica, MA, USA). After the blockage with 5\% nonfat dry milk for $1 \mathrm{~h}$, the blotting membranes were incubated with specific primary antibodies overnight at $4^{\circ} \mathrm{C}$, respectively. GAPDH was used as loading control. The primary antibodies were as follows: rabbit anti-active-Caspase-3 (Abcam, Cambridge, UK; ab2302, 1:200), anti-Bax (Abcam; ab32503, 1:2,000), anti-Bcl-2 (Abcam; ab59348, 1:1,000), anti-ERK1/2 (Abcam; ab17942, 1:1,000), anti-p-ERK1/2 (Cell Signaling Technology, Inc., Danvers, MA, USA; 4370, 1:2,000), anti-GAPDH (Abcam; ab9485, 1:2,500). After that, membranes were incubated with the appropriate secondary antibody goat anti-rabbit HRP-conjugated
IgG H\&L (Abcam; ab6721, 1:5,000) for $2 \mathrm{~h}$. The PVDF membrane were exposed to and detected by X-ray film with enhanced chemiluminescense (ECL) detection system reagents (Amersham; GE Healthcare, Chalfont, UK).

Statistical analysis. All results were presented as mean \pm standard deviation of three independent experiments. Statistical analysis was performed using a SPSS 22.0 statistical package (IBM Corp., Armonk, NY, USA), then differences among multi-groups were analyzed by Welch's one-way analysis of variance (ANOVA), following by Games-Howell test. $\mathrm{P}<0.05$ was considered significant, $\mathrm{P}<0.01$ was considered especially significant.

\section{Results}

LBP promoted cell viability of hippocampal neurons injured by sevoflurane. Hippocampal primary neurons were isolated from SD embryonic rats and cell morphologies were found in good growing conditions after 3 and 7 days culture, observed by light microscopy. On the 3rd day, most of cells displayed classical morphologies of neural cells, with round, oval or shuttle shapes, smooth surface, longer neurites with obvious branches connected to be nets. On the 7th day, neurons aggregated with shuttle or polygonal shapes, with more neurites tightly connected to be nets, indicating the rapid brain development period which was vulnerable to anesthesia-induced neuronal injury (Fig. 1A).

CCK-8 assay was used to detect function of LBP with different concentrations $(100,200,400$ and $600 \mu \mathrm{g} / \mathrm{ml})$ on cell viability of hippocampal primary neurons treated with $3 \%$ 

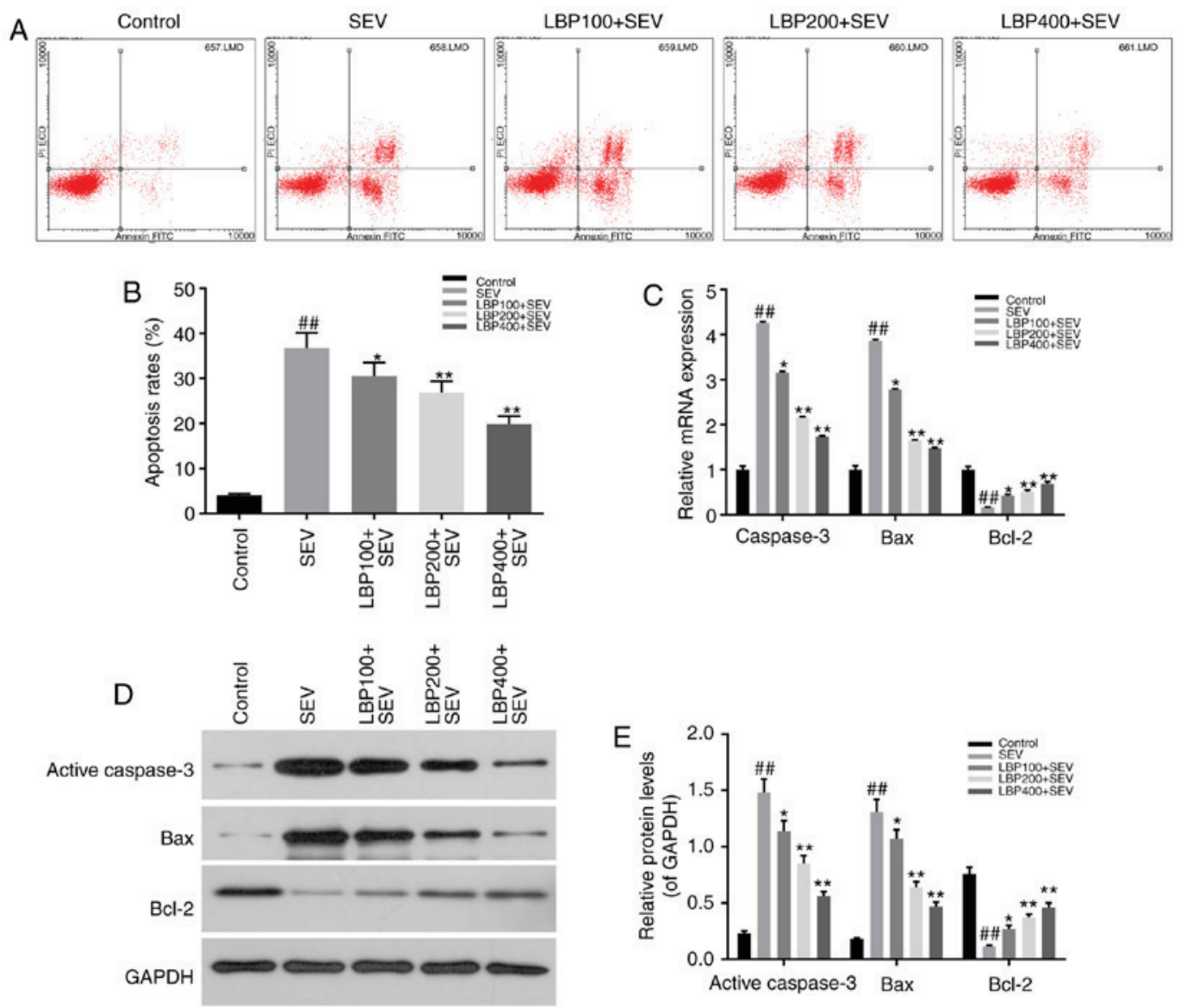

Figure 2. LBP inhibited cell apoptosis of hippocampal neurons injured by sevoflurane. (A and B) Annexin V/PI double-stain and FCM assay were performed to evaluate the effect of LBP with different concentrations (100, 200 and $400 \mu \mathrm{g} / \mathrm{ml})$ on cell apoptosis of neurons injured by $3 \%$ sevoflurane for $6 \mathrm{~h}$. (C-E) The expression levels of apoptosis related factors, such as Caspase-3, Bax, Bcl-2, were determined by (C) RT-qPCR and (D and E) western blot analysis in above groups. ${ }^{\# \#} \mathrm{P}<0.01$ vs. Control group, ${ }^{*} \mathrm{P}<0.05,{ }^{* *} \mathrm{P}<0.01$ vs. SEV group. LBP, Lycium barbarum polysaccharides; FCM, flow cytometry.

sevoflurane, at determined times $(2,4$ and 6 h). Function of $400 \mu \mathrm{g} / \mathrm{ml}$ LBP alone was also detected. LBP alone had no effect on neurons viability. Cell viability of neurons decreased significantly with sevoflurane treatment, compared with control group $(\mathrm{P}<0.01)$. The inhibition rate of $3 \%$ sevoflurane on neurons viability was $53 \%$ at $6 \mathrm{~h}$, so $3 \%$ sevoflurane treatment for $6 \mathrm{~h}$ was chosen for following experiments. Meanwhile cell viability of sevoflurane-injured neurons increased notably by LBP in dose $(100,200,400$ and $600 \mu \mathrm{g} / \mathrm{ml})$ and time dependent $(2,4$, $6 \mathrm{~h})$ manners, compared with SEV group $(\mathrm{P}<0.05)$ (Fig. 1B). For the effect of $600 \mu \mathrm{g} / \mathrm{ml}$ was similar to $400 \mu \mathrm{g} / \mathrm{ml} \mathrm{LBP}$, we just studied function of LBP $(100,200$ and $400 \mu \mathrm{g} / \mathrm{ml})$ in the following experiments.

CFSE assay was conducted to verify the promotion function of LBP with different concentrations (100, 200 and $400 \mu \mathrm{g} / \mathrm{ml})$ on cell proliferation abilities of hippocampal primary neurons treated by $3 \%$ sevoflurane for $6 \mathrm{~h}$. The flow cytometry (FCM) detection showed that the cell proliferation ability of neurons was inhibited significantly, with decreased M1 values, by sevoflurane in SEV group, compared with control group $(\mathrm{P}<0.01)$, which was promoted significantly, with increased M1 values, by LBP in dose-dependent manners (100, 200 and $400 \mu \mathrm{g} / \mathrm{ml})$ $(\mathrm{P}<0.05$; Fig. 1C and D).

LBP inhibited cell apoptosis of hippocampal neurons injured by sevoflurane. Annexin V/PI double-stain and FCM assay
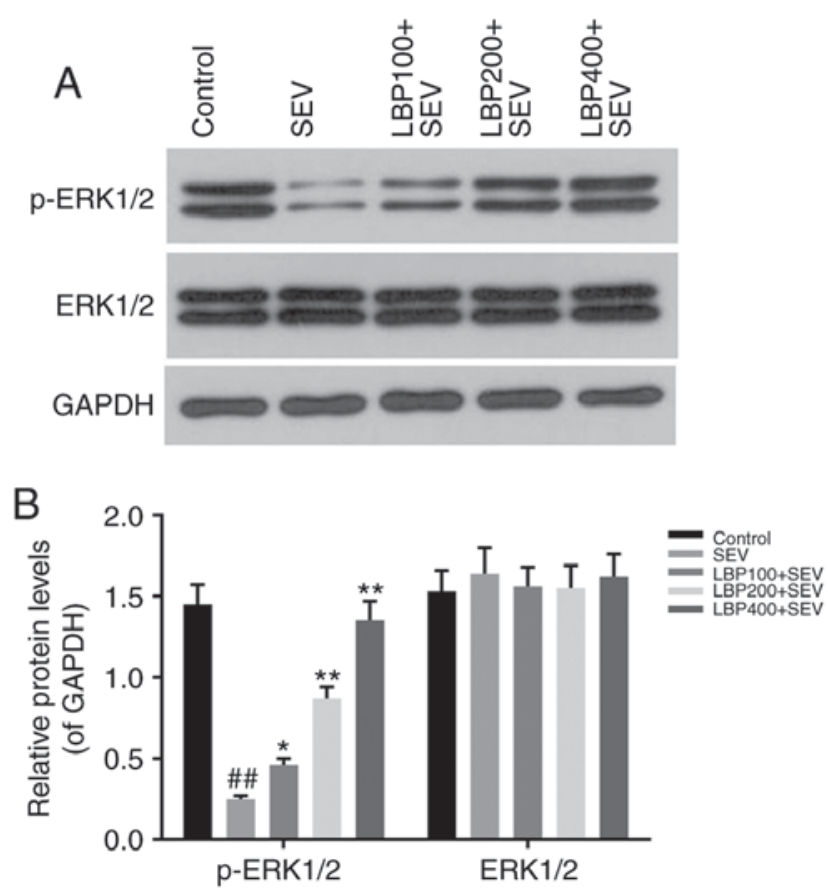

Figure 3. LBP activated ERK1/2 pathway in hippocampal neurons injured by sevoflurane. The phosphorylation levels of ERK1/2 were assessed by western blot in Control, SEV, LBP100+SEV, LBP200+SEV, LBP400+SEV groups. ${ }^{\# \# ~ P<0.01 ~}$ vs. Control group, ${ }^{*} \mathrm{P}<0.05,{ }^{* *} \mathrm{P}<0.01$ vs. SEV group. LBP, Lycium barbarum polysaccharides; ERK1/2, extracellular signal-regulated kinase 1/2. 

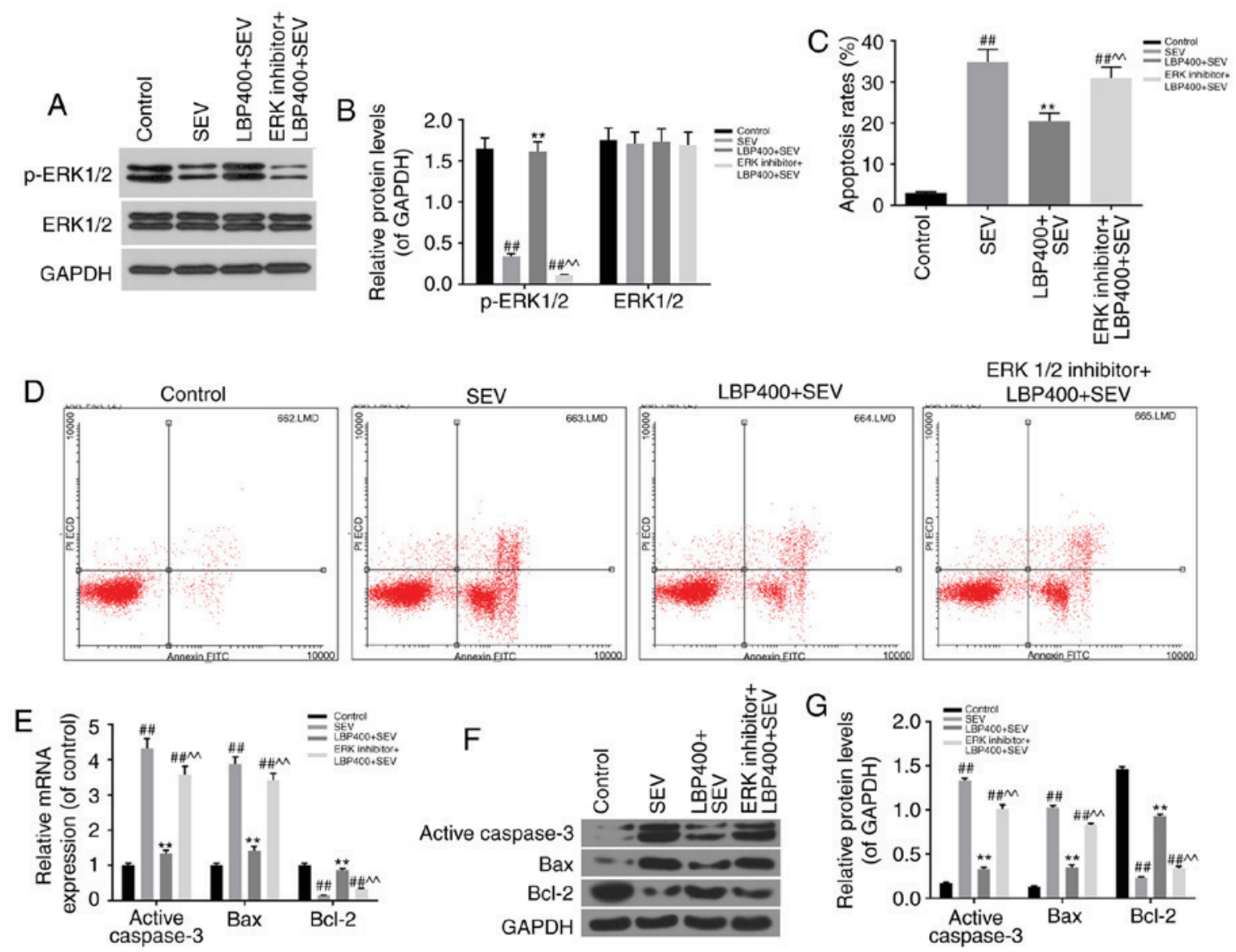

Figure 4. LBP inhibited cell apoptosis through ERK1/2 pathway in sevoflurane injured hippocampal neurons, which was verified by ERK1/2 inhibitor usage. (A and B) Western blot analysis was performed to analyze levels of pERK1/2 protein levels in Control, SEV, LBP400+SEV, ERK1/2 inhibitor+LBP400+SEV groups. (C and D) The FCM analysis was conducted to analyze the apoptosis rates in above groups. (E) RT-qPCR and (F and G) western blot analysis were conducted to analyze levels of apoptosis related factors in above groups. ${ }^{\# *} \mathrm{P}<0.01$ vs. Control group, ${ }^{* * *} \mathrm{P}<0.01 \mathrm{vs}$. SEV group, ${ }^{\wedge} \mathrm{P}<0.01$ vs. LBP400+SEV group. LBP, Lycium barbarum polysaccharides; ERK1/2, extracellular signal-regulated kinase 1/2.

were performed to evaluate the effect of LBP with different concentrations $(100,200$ and $400 \mu \mathrm{g} / \mathrm{ml})$ on cell apoptosis status of hipocampal neurons injured by $3 \%$ sevoflurane for $6 \mathrm{~h}$. The results suggested that sevoflurane remarkably facilitated cell apoptosis of neurons in SEV group, compared with control group $(\mathrm{P}<0.01)$, which was reduced notably by LBP in dose-dependent manners $(100,200$ and $400 \mu \mathrm{g} / \mathrm{ml})(\mathrm{P}<0.05$; Fig. 2A and B).

The expression levels of apoptosis related factors, such as active-Caspase-3, Bax, Bcl-2, were determined by RT-qPCR and western blot assay in above groups. The results demonstrated that sevoflurane dramatically up-regulated the expression levels of pro-apoptosis factors active $=$ Caspase -3 and $\mathrm{Bax}(\mathrm{P}<0.01)$, and LBP effectively down-regulated them dose-dependently $(100,200$ and $400 \mu \mathrm{g} / \mathrm{ml})$, both in mRNA and protein manners $(\mathrm{P}<0.05)$. Meanwhile, sevoflurane notably down-regulated the expression of apoptosis inhibitor Bcl-2 $(\mathrm{P}<0.01)$, and LBP effectively up-regulated them dose-dependently (100, 200 and $400 \mu \mathrm{g} / \mathrm{ml}$ ), both in mRNA and protein manners (P<0.05; Fig. 2C-E).

LBP activated ERK1/2 pathway in hippocampal neurons injured by sevoflurane. The phosphorylation levels of ERK1/2 in above groups were assessed by western blot. The assay illustrated that, protein levels of p-ERK1/2 decreased significantly in SEV group compared with control group $(\mathrm{P}<0.01)$, which increased notably dose-dependently (100, 200 and $400 \mu \mathrm{g} / \mathrm{ml})$ when treated with LBP, compared with SEV group $(\mathrm{P}<0.05)$. Meanwhile, t-ERK1/2 levels were of no significant differences among different groups (Fig. 3A and B).

ERK1/2 inhibitor blocked function of LBP on sevoflurane injured hippocampal neurons. Western blot assay on ERK1/2 protein levels in Control, SEV, LBP400+SEV, ERK1/2 inhibitor+LBP400+SEV groups revealed that, the increased protein levels of p-ERK1/2 in LBP400+SEV group was blocked when pre-treated with ERK1/2 inhibitor $(\mathrm{P}<0.05)$ (Fig. 4A and B). The FCM analysis on apoptosis rates verified that, LBP declined the apoptosis rates of hippocampal neurons treated with sevoflurane in LBP400+SEV group, which was attenuated by ERK1/2 inhibitor $(\mathrm{P}<0.05)$ (Fig. $4 \mathrm{C}$ and $\mathrm{D}$ ). RT-qPCR and western blot assays showed that levels of active $=$ Caspase -3 and Bax were promoted, $\mathrm{Bcl}-2$ was inhibited by ERK1/2 inhibitor in ERK1/2 inhibitor+LBP400+SEV group, compared with LBP400+SEV group $(\mathrm{P}<0.05)$ (Fig. 4E-G).

\section{Discussion}

Sevoflurane, commonly used as inhalational anesthetics in cesarean delivery and pediatric surgeries, is reported to frequently induce behavioral and developmental cognitive 
disorders in children. It is necessary to find possible remedy to prevent developmental anesthetic neurotoxicity. LBPs are effective to enhance neurogenesis in hippocampus and to improve cognition via apoptosis regulation in hippocampal neurons under stress. It is exciting to verify the possible molecular mechanism of LBP protecting neurons from sevoflurane injury.

The hippocampus is the critical tissue for spatial navigation and long-term memory in brain. In the present study, the primary hippocampal neurons isolated from SD embryonic rats were observed by light microscopy after culture for 3 and 7 days. Then neurons cultured for 7 days were chosen for the following research, for the best developing morphologies with much more tightly connected neurites. LBP alone didn't affect cell viabilities of hippocampal neurons. 3\% seveflurane was used to construct the injury model in the studies before $(6,26)$, Moreover, the inhibition rate of 3\% sevoflurane on neurons viability at $6 \mathrm{~h}$ was $53 \%$, so $3 \%$ sevoflurane treatment for $6 \mathrm{~h}$ was chosen for following experiments. Cell differentiation happens along with the whole process of neurons development. As a spontaneous cell-suicide process, apoptosis of neurons is needed for regular brain development. However, abnormal apoptosis could inhibit cell viability too. In our study, LBP was found promoting cell viability, proliferation, and inhibiting cell apoptosis of neurons injured by $3 \%$ seveflurane dose-dependently (100, 200 and $400 \mu \mathrm{g} / \mathrm{ml})$.

Sevoflurane neurotoxicity in immature brain is related to excessive apoptosis, including abnormal expression of $\mathrm{Bcl}-2$ family members and caspases (25). The members of Bcl-2 family, including Bax, Bcl-2 and Bcl-XL, are the main regulators of apoptosis $(30,31)$. As a critical anti-apoptosis factor, Bcl-2 inhibits apoptosis predominantly by inhibiting caspase pathway. On the other hand, Bax conjugates with Bcl-2, forming heterodimer, to induce the release of cytochrome c, activate caspase pathway and promote apoptosis $(32,33)$. Caspases are a family of cysteine-aspartic proteases. Being the final executor of caspase pathway, caspase- 3 plays an important role to degrade cellular components and induce apoptosis (34). Consistent with previous researches, our study showed that sevoflurane-treatment on hippocampal neurons significantly increased the expression levels of pro-apoptosis factors like Bax and active-Caspase-3, and decreased the expression levels of anti-apoptosis factors such as Bcl-2. It showed that, LBP promoted cell viability and differentiation, inhibited apoptosis dose-dependently by declining Bcl-2 and elevating Bax and active-Caspase-3 expression, in hippocampal neurons injured by sevoflurane in our study, as expected.

Recently, studies have provided evidence that numerous pathways were involved in sevoflurane induced injury on neurons (35). ERK1/2 MAPK pathway is activated by different stimulus including growing factors, mechanical stress and so on (36). The activation of ERK1/2 is necessary for signal transduction, from cell membrane surface receptors to nucleus. ERK1/2 MAPK signaling pathway has been reported to play essential roles in developmental neuronal survival and sevoflurane neurotoxicity (6-8), to increase dendritic spine density during synaptogenesis in hippocampal neurons, and to help improving learning and memory abilities $(37,38)$. MEK (ERK1/2 kinase) inhibitor PD98059 is specific for ERK1/2 pathway, by noncompetitively binding to MEK, it is commonly used to block ERK1/2 pathway. In our study, LBP was found effectively promoting ERK1/2 activation by increasing ERK1/2 phosphorylation levels, which was decreased remarkably by sevoflurane in hippocampal neurons. The phosphorylation levels of ERK1/2 were attenuated when additional ERK1/2 inhibitor PD98059 was applied. Furthermore, ERK1/2 inhibitor could attenuate function of LBP on apoptosis inhibition, in hippocampal neurons treated with sevoflurane. Consistent with the promoted apoptosis, the expression levels of Bax and active-Caspase increased, and Bcl-2 decreased when ERK1/2 inhibitor existed, Though it would be better to investigate effect of ERK1/2 activation on it at the same time, the results have indicated that LBP protected neurons from sevoflurane induced apoptosis through ERK1/2 pathway, which might attenuate cell viability and proliferation abilities of primary hippocampal neurons.

Based on the whole study, LBP could promote cell viability, cell proliferation and inhibit apoptosis of primary hippocampal neurons injured by sevoflurane, through activating ERK1/2 MAPK pathway. Moreover additional ERK1/2 inhibitor could attenuate function of LBP by promoting cell apoptosis. It provided novel light to attenuate neurotoxicity of inhalational anesthetics in clinic. Function of LBP on sevoflurane-induced behavioral changes, cognitive and memorial disorders in vivo might be further studied in the future.

\section{Acknowledgements}

Not applicable.

\section{Funding}

No funding was received.

\section{Availability of data and materials}

All data generated or analyzed during this study are included in this published article.

\section{Authors' contributions}

XW designed the study, conducted the cell culture and wrote the manuscript. YX performed the CFSE, apoptosis analysis, and detected apoptosis-associated factors and ERK1/2 phosphorylation.

\section{Ethics approval and consent to participate}

The present study was approved by Institutional Animal Care and Use Committee of Qinghai Red Cross Hospital (Qinghai, China; Approval No. Z20160612).

\section{Patient consent for publication}

Not applicable.

\section{Competing interests}

The authors declare that they have no competing interests. 


\section{References}

1. Dobbing J and Sands J: Comparative aspects of the brain growth spurt. Early Hum Dev 3: 79-83, 1979.

2. Yon JH, Daniel-Johnson J, Carter LB and Jevtovic-Todorovic V: Anesthesia induces neuronal cell death in the developing rat brain via the intrinsic and extrinsic apoptotic pathways. Neuroscience 135: 815-827, 2005.

3. DiMaggio C, Sun LS, Kakavouli A, Byrne MW and Li G: A retrospective cohort study of the association of anesthesia and hernia repair surgery with behavioral and developmental disorders in young children. J Neurosurg Anesthesiol 21: 286-291, 2009.

4. Wilder RT, Flick RP, Sprung J, Katusic SK, Barbaresi WJ, Mickelson C, Gleich SJ, Schroeder DR, Weaver AL and Warner DO: Early exposure to anesthesia and learning disabilities in a population-based birth cohort. Anesthesiology 110: 796-804, 2009.

5. Servick K: Biomedical research. Researchers struggle to gauge risks of childhood anesthesia. Science 346: 1161-1162, 2014.

6. Wang WY, Wang H, Luo Y, Jia LJ, Zhao JN, Zhang HH, Ma ZW, Xue QS and Yu BW: The effects of metabotropic glutamate receptor 7 allosteric agonist N,N'-dibenzhydrylethane-1,2-diamine dihydrochloride on developmental sevoflurane neurotoxicity: Role of extracellular signal-regulated kinase 1 and 2 mitogen-activated protein kinase signaling pathway. Neuroscience 205: 167-177, 2012.

7. Wang WY, Yang R, Hu SF, Wang H, Ma ZW and Lu Y: $\mathrm{N}$-stearoyl-L-tyrosine ameliorates sevoflurane induced neuroapoptosis via MEK/ERK1/2 MAPK signaling pathway in the developing brain. Neurosci Lett 541: 167-172, 2013.

8. Wang WY, Jia LJ, Luo Y, Zhang HH, Cai F, Mao H, Xu WC, Fang JB, Peng ZY, Ma ZW, et al: Location- and subunit-specific NMDA receptors determine the developmental sevoflurane neurotoxicity through ERK1/2 signaling. Mol Neurobiol 53: 216-230, 2016.

9. Edwards DA, Shah HP, Cao W, Gravenstein N, Seubert CN and Martynyuk AE: Bumetanide alleviates epileptogenic and neurotoxic effects of sevoflurane in neonatal rat brain. Anesthesiology 112: $567-575,2010$.

10. Shih J, May LD, Gonzalez HE, Lee EW, Alvi RS, Sall JW, Rau V, Bickler PE, Lalchandani GR, Yusupova M, et al: Delayed environmental enrichment reverses sevoflurane-induced memory impairment in rats. Anesthesiology 116: 586-602, 2012.

11. Lu Y, Wu X, Dong Y, Xu Z, Zhang Y and Xie Z: Anesthetic sevoflurane causes neurotoxicity differently in neonatal naive and Alzheimer disease transgenic mice. Anesthesiology 112: 1404-1416, 2010.

12. Satomoto M, Satoh Y, Terui K, Miyao H, Takishima K, Ito M and Imaki J: Neonatal exposure to sevoflurane induces abnormal social behaviors and deficits in fear conditioning in mice. Anesthesiology 110: 628-637, 2009.

13. Zhang M, Chen H, Huang J, Li Z, Zhu C and Zhang S: Effect of Lycium barbarum polysaccharide on human hepatoma QGY7703 cells: Inhibition of proliferation and induction of apoptosis. Life Sci 76: 2115-2124, 2005 .

14. Chang RC and So KF: Use of anti-aging herbal medicine, Lycium barbarum, against aging-associated diseases. What do we know so far? Cell Mol Neurobiol 28: 643-652, 2008.

15. Li XM, Ma YL and Liu XJ: Effect of the Lycium barbarum polysaccharides on age-related oxidative stress in aged mice. J Ethnopharmacol 111: 504-511, 2007.

16. Cheng D and Kong H: The effect of Lycium barbarum polysaccharide on alcohol-induced oxidative stress in rats. Molecules 16: 2542-2550, 2011

17. Tang WM, Chan E, Kwok CY, Lee YK, Wu JH, Wan CW, Chan RY, Yu PH and Chan SW: A review of the anticancer and immunomodulatory effects of Lycium barbarum fruit. Inflammopharmacology 20: 307-314, 2012.

18. Li SY, Yang D, Yeung CM, Yu WY, Chang RC, So KF, Wong D and Lo AC: Lycium barbarum polysaccharides reduce neuronal damage, blood-retinal barrier disruption and oxidative stress in retinal ischemia/reperfusion injury. PLoS One 6: e16380, 2011.

19. Luo Q, Cai Y, Yan J, Sun M and Corke H: Hypoglycemic and hypolipidemic effects and antioxidant activity of fruit extracts from Lycium barbarum. Life Sci 76: 137-149, 2004.

20. Li H, Liang Y, Chiu K, Yuan Q, Lin B, Chang RC and So KF: Lycium barbarum (wolfberry) reduces secondary degeneration and oxidative stress, and inhibits JNK pathway in retina after partial optic nerve transection. PLoS One 8: e68881, 2013.

21. Lau BW, Lee JC, Li Y, Fung SM, Sang YH, Shen J, Chang RC and So KF: Polysaccharides from wolfberry prevents corticosterone-induced inhibition of sexual behavior and increases neurogenesis. PLoS One 7: e33374, 2012.
22. Chen W, Cheng X, Chen J, Yi X, Nie D, Sun X, Qin J, Tian M, Jin G and Zhang X: Lycium barbarum polysaccharides prevent memory and neurogenesis impairments in scopolamine-treated rats. PLoS One 9: e88076, 2014.

23. Gao J, Chen C, Liu Y, Li Y, Long Z, Wang H, Zhang Y, Sui J, Wu Y, Liu L and Yang C: Lycium barbarum polysaccharide improves traumatic cognition via reversing imbalance of apoptosis/regeneration in hippocampal neurons after stress. Life Sci 121: 124-134, 2015.

24. Zhao P, Ma NT, Chang RY, Li YX, Hao YJ, Yang WL, Zheng J, Niu Y, Sun T and Yu JQ: Mechanism of Lycium barbarum polysaccharides on primary cultured rat hippocampal neurons. Cell Tissue Res 369: 455-465, 2017.

25. Zhang X, Xue Z and Sun A: Subclinical concentration of sevoflurane potentiates neuronal apoptosis in the developing C57BL/6 mouse brain. Neurosci Lett 447: 109-114, 2008

26. Ling Y, Li X, Yu L, Liang Q, Lin X, Yang X, Wang H and Zhang Y: Sevoflurane exposure in postnatal rats induced long-term cognitive impairment through upregulating caspase-3/cleaved-poly (ADP-ribose) polymerase pathway. Exp Ther Med 14: 3824-3830, 2017.

27. Beccari S, Valero J, Maletic-Savatic M and Sierra A: A simulation model of neuroprogenitor proliferation dynamics predicts age-related loss of hippocampal neurogenesis but not astrogenesis. Sci Rep 7: 16528, 2017

28. Wu BW, Wu MS and Guo JD: Effects of microRNA-10a on synapse remodeling in hippocampal neurons and neuronal cell proliferation and apoptosis through the BDNF-TrkB signaling pathway in a rat model of Alzheimer's disease. J Cell Physiol: Dec 7, 2017 (Epub ahead of print).

29. Yan BC, Jiang D, Wang J,Zhang Y, Zhu X, Xu P, Yu X, Won MH and Su PQ: Both decreased Akt expression and mTOR phosphorylation are related to decreased neuronal differentiation in the hippocampal alveus of aged mice. Aging Clin Exp Res: Oct 13, 2017 (Epub ahead of print)

30. Park JW, Lim MS, Ji SY, Cho MS, Park SJ, Han SH and Kim JH: Effects of short-term exposure to sevoflurane on the survival, proliferation, apoptosis, and differentiation of neural precursor cells derived from human embryonic stem cells. J Anesth 31: 821-828, 2017.

31. Ozer AB, Ceribasi S, Ceribasi AO, Demirel I, Bayar MK, Ustundag B, Ileri A and Erhan OL: Effects of sevoflurane on apoptosis, BDNF and cognitive functions in neonatal rats. Bratisl Lek Listy 118: 80-84, 2017.

32. Yang X, Yang S, Hong C, Yu W and Guonian W: Panax Notoginseng Saponins attenuates sevoflurane-induced nerve cell injury by modulating AKT signaling pathway. Mol Med Rep 16: 7829-7834, 2017.

33. Ding ML, Ma H, Man YG and Lv HY: Protective effects of a green tea polyphenol, epigallocatechin-3-gallate, against sevoflurane-induced neuronal apoptosis involve regulation of $\mathrm{CREB} / \mathrm{BDNF} / \mathrm{TrkB}$ and $\mathrm{PI} 3 \mathrm{~K} / \mathrm{Akt} / \mathrm{mTOR}$ signalling pathways in neonatal mice. Can J Physiol Pharmacol 95: 1396-1405, 2017.

34. Huang H, Liu CM, Sun J, Jin WJ, Wu YQ and Chen J: Repeated 2\% sevoflurane administration in 7 and 60-day-old rats: Neurotoxicity and neurocognitive dysfunction. Anaesthesist 66: 850-857, 2017.

35. Seutin VM: Mechanisms of actions of inhaled anesthetics. N Engl J Med 349: 909-910, 2003

36. Geng Y, Zhou Y, Wu S, Hu Y, Lin K, Wang Y, Zheng Z and Wu W: Sulforaphane induced apoptosis via promotion of mitochondrial fusion and ERK1/2-mediated 26S proteasome degradation of novel pro-survival bim and upregulation of bax in human non-small cell lung cancer cells. J Cancer 8: 2456-2470, 2017.

37. Alonso M, Medina JH and Pozzo-Miller L: ERK1/2 activation is necessary for BDNF to increase dendritic spine density in hippocampal CA1 pyramidal neurons. Learn Mem 11: 172-178, 2004.

38. Adams JP and Sweatt JD: Molecular psychology: Roles for the ERK MAP kinase cascade in memory. Annu Rev Pharmacol Toxicol 42: 135-163, 2002.

This work is licensed under a Creative Commons Attribution-NonCommercial-NoDerivatives 4.0 International (CC BY-NC-ND 4.0) License. 